\title{
SCREENING OF SOME BIOLOGICAL ACTIVITIES OF ALYSSUM FULVESCENS VAR. FULVESCENS KNOWN AS EGE MADWORT
}

\author{
Cennet OzaY* and Ramazan Mammadov \\ Department of Biology, Faculty of Science and Literature, Pamukkale University, \\ 20070, Denizli, Turkey
}

(Received: March 25, 2017; accepted: May 2, 2017)

\begin{abstract}
In this research, the phenolic composition, antioxidant, antibacterial and cytotoxic activities of the methanolic extracts obtained from Alyssum fulvescens var. fulvescens aerial parts known as Ege kuduzotu in western Turkey, were firstly investigated. The antioxidant activity of the extract was determined by DPPH, metal chelating, phosphomolybdenum, $\beta$-carotene/linoleic acid and ferric reducing power assays. Moreover, total phenolic and flavonoid contents in the extract were investigated. The brine shrimp (Artemia salina L.) lethality test was used to investigate for the possible cytotoxic activity of the extract. Microdilution broth method was used to study antibacterial potency of extract against Gram-positive and Gram-negative bacteria. The extract exhibited good biological activities. Total phenolic and flavonoid contents in the extract were significantly correlated with antioxidant potentials. HPLC analysis showed that chlorogenic acid was the major phenolic in extract tested. The results indicated that the extract of A. fulvescens var. fulvescens may be considered as a potential source of biological agents and in vivo investigations are needed to test the biological effects of $A$. fulvescens var. fulvescens.
\end{abstract}

Keywords: Alyssum fulvescens var. fulvescens - antioxidant activity - cytotoxicity - phenolic composition - HPLC

\section{INTRODUCTION}

The family Brassicaceae consists of about 400 genera and 4000 species, and includes several genera such as Crambe, Sinapis, Thlaspi, Alyssum and Brassica. Many Brassicaceae species are known for their use in folk medicine as antimicrobial agent for relief of biliary colic and wound sores [11]. The genus Alyssum L. is one of the biggest genera, which include many species in Turkey. It is represented by 90 species and 54 of them are endemic [5].

The name Alyssum is of Greek derivation: $a$ meaning not, and lyssa alluding madness, rage or hydrophobia. Accordingly, the names Madwort and Alyssum both refer to the plant's reputation as an officinal herb in Europe and North America. An infusion concocted from the leaves and flowers was reputed to have been administered as a specific antidote against madness or the bite of a rabid dog. Some sources have

\footnotetext{
*Corresponding author; e-mail address: cennetozay@hotmail.com
} 
suggested the use of Alyssum tea as a sedative for allaying anger [8]. Shimer [27], has indicated that Alyssum was used by the Greeks as a remedy for hiccoughs. Although there are no reports of the medicinal uses of Alyssum fulvescens Sibth. \& Sm. var. fulvescens, the aerial parts of $A$. constelletum Boiss. are used in tea form as a demulcent in Turkey [18]. Brassicaceae plants have evolved the ability to synthesis a wide range of sulfur-containing secondary metabolites, including glucosinolates and indole-type phytoalexins [3]. Previous studies have shown that Alyssum genus contains glucosinolates, hydrocarbons, fatty acids and phenolics $[10,23,30]$.

As it is known, the secondary metabolites such as polyphenols, flavonoids, terpenes, saponins and alkaloids are primarily responsible constituents that contributes the biological potential of various plants [16]. Therefore, this study was centered upon the analysis of the phenolic content, antibacterial, antioxidant and cytotoxic activity of the methanolic extract from A. fulvescens var. fulvescens. Several studies have been published in which antioxidant, antibacterial and cytotoxic activities of different plant species are studied but as far as our literature survey could as certain, there are no reports on the biological activities and phenolic composition of $A$. fulvescens var. fulvescens. Thus, this study is the first report on this plant.

\section{MATERIALS AND METHODS}

\section{Plant material and extraction procedure}

A. fulvescens var. fulvescens was collected in April 2013 from İzmir-Turkey (Yamanlar Mountain, $800 \mathrm{~m}$ ) and identified in our laboratory (Voucher No: C. OZAY1003). Ten g of air-dried aerial parts of the plant were extracted with $100 \mathrm{~mL}$ methanol in a shaker water bath at $50{ }^{\circ} \mathrm{C}$ for $6 \mathrm{~h}$. The extraction was repeated twice at the same condition [24]. The extract was filtered with Whatman No. 1 filter paper and methanol was evaporated at $40^{\circ} \mathrm{C}$ by using a rotary evaporator. Residual part of the extract was dissolved with water and the water in the extract was lyophilized. Anhydrous extract was stored at $-20^{\circ} \mathrm{C}$ until analysis.

\section{Antioxidant activity}

\section{Phosphomolybdenum method}

The total antioxidant capacity of extract was evaluated by phosphomolybdenum method according to Prieto et al. [25], $0.3 \mathrm{~mL}$ of extract solution $(1 \mathrm{mg} / \mathrm{mL})$ was mixed with $3 \mathrm{~mL}$ of reagent solution. The reaction mixture was incubated at $95{ }^{\circ} \mathrm{C}$ for $90 \mathrm{~min}$. Then, the absorbance of the solution was measured at $695 \mathrm{~nm}$ against blank. The antioxidant capacity of the extract was expressed as equivalents of ascorbic acid (mgAEs/g). 


\section{DPPH free-radical scavenging activity}

The effect of methanol extract on 2,2-diphenyl-1-picrylhydrazyl (DPPH) radical was estimated according to Wu et al. [31]. Four ml of the DPPH's 0.004\% metanolic solution was mixed with $1 \mathrm{~mL}(0.2-1.0 \mathrm{mg})$ of the extracts, and their absorbances were measured at $517 \mathrm{~nm}$ after incubation for $30 \mathrm{~min}$ at room temperature in dark. BHT and BHA were used as standarts.

\section{Reducing power activity (iron (III) to iron (II) reduction)}

The ferric reducing power method was applied with slight modifications of the method of Oyaizu [22]. Various concentrations of extract $(2.5 \mathrm{~mL})$ were mixed with $2.5 \mathrm{~mL}, 0.2 \mathrm{M}$ phosphate buffer ( $\mathrm{pH} 6.6$ ) and $2.5 \mathrm{~mL}$ of $1 \%$ potassium ferricyanide. The mixture was incubated at $50{ }^{\circ} \mathrm{C}$ for $20 \mathrm{~min}$. After, $2.5 \mathrm{~mL}$ of $10 \%$ trichloroacetic acid was added. The $2.5 \mathrm{~mL}$ of the reaction mixture was mixed with $2.5 \mathrm{~mL}$ distilled water and $0.5 \mathrm{~mL}$ of $0.1 \%$ ferric chloride. The solution absorbance was measured at $700 \mathrm{~nm} . \mathrm{EC}_{50}$ of the plant extract was then determined. BHT and BHA were used as standarts.

\section{$\beta$-Carotene-linoleic acid assay}

In this assay, antioxidant capacity of extract was determined by slight modifications of the procedure described by Sokmen et al. [29]. Antioxidant activity (AA) was calculated in following way:

$$
\text { AA: }\left[1-\left(\mathrm{A}_{0}-\mathrm{A}_{\mathrm{t}} / \mathrm{A}_{0}{ }^{\mathrm{o}}-\mathrm{A}_{\mathrm{t}}{ }^{\circ}\right)\right] \times 100
$$

where $A_{0}$ is the initial absorbance of the sample, $A_{t}$ is the initial absorbance of the control, $\mathrm{A}_{0}{ }^{\circ}$ is the sample's absorbance after 120 min, and $\mathrm{A}_{\mathrm{t}}{ }^{\circ}$ is the control's absorbance after $120 \mathrm{~min}$.

\section{Metal chelating activity on ferrous ions}

The metal chelating activity on ferrous ions was determined by the method described by Aktumsek et al. [1] and expressed as equivalents of EDTA (mg EDTAEs/g). 


\section{Total phenolic content (Folin-Ciocalteu assay)}

Total phenolic content of the extract was analyzed via Folin-Ciocalteu method which gallic acid was used as a standart [28]. One $\mathrm{mL}$ of extract solution $(1 \mathrm{mg})$ was added to $46 \mathrm{~mL}$ of distilled water and $1 \mathrm{~mL}$ of Folin-Ciocalteu reagent and was mixed properly. After $3 \mathrm{~min}$, the mixture was added to $3 \mathrm{~mL}$ of sodium carbonate (2\%) and shaken intermittently for $2 \mathrm{~h}$. The absorbance was read at $760 \mathrm{~nm}$ and the total phenolic content was expressed as equivalents of gallic acid (mgGAEs/g).

\section{Total flavonoid content}

Total flavonoid content of the extract was determined by the aluminium colorimetric method [2] and expressed as equivalents of quercetin (mg QEs/g).

\section{Quantification of phenolic compounds by RP-HPLC}

HPLC analysis was carried out on Shimadzu LC-20AT Prominence (Shimadzu, Japan). Separations were carried out at $30^{\circ} \mathrm{C}$ on C-18 reversed-phase column (250 $\mathrm{mm} \times 4.6 \mathrm{~mm}$ length, $5 \mu \mathrm{m}$ particle size). The mobile phases were A: $3.0 \%$ formic acid in distilled water and B: methanol. Methanol was used to dissolve samples, and then $20 \mu \mathrm{L}$ of this solution was injected into the column. Phenolic composition of the extract was determined according to the method of Caponio et al. [4] with slight modification. Gallic acid, protocatechuic acid, 4-hydroxybenzoic acid, chlorogenic acid, vanillic acid, caffeic acid, $p$-coumaric acid, ferulic acid and cinnamic acid were used as standard. The differentiation and quantitative analysis were made by comparing the standards. The quantity of each phenolic compound was expressed as mg per gram of the extract.

\section{Antibacterial activity}

The extract was tested against different microorganisms, including P. aeruginosa, E. coli, $S$. enteritidis, M. luteus, $S$. aureus and B. subtilis by means of microdilution broth method [20]. Bacterial strains were cultured on Mueller Hinton agar for $24 \mathrm{~h}$, at $37^{\circ} \mathrm{C}$. Test strains were suspended in Mueller Hinton broth to give a final density of $5 \times 10^{5} \mathrm{cfu} / \mathrm{ml}$ and these were confirmed by viable counts. Dilutions ranging from $4.50 \mathrm{mg} / \mathrm{mL}$ to $100 \mathrm{mg} / \mathrm{mL}$ of the extract were prepared in a 96-well microtiter plate. Plates were incubated at $37^{\circ} \mathrm{C}$ for $24 \mathrm{~h}$. Bacterial density was then measured at 610 $\mathrm{nm}$ to determine minimum inhibitory concentration (MIC). Antimicrobial activities of gentamicin and oxacillin were determined as positive controls in parallel experiments. 


\section{Brine shrimp (Artemia salina L.) lethality test}

Brine shrimp lethality test (BSLT) was applied to analyze the possible cytotoxic activity of the extracts. A. salina eggs were incubated in seawater at $28^{\circ} \mathrm{C}$. After incubation for $24 \mathrm{~h}$, larvae were collected and kept for an additional $24 \mathrm{~h}$ under the same conditions to reach the mature larvae stage. Ten larvae were drawn with a pasteur pipette and placed in every test tube containing $4.5 \mathrm{~mL}$ of brine solution. In each experiment, $0.5 \mathrm{~mL}$ of the plant extract was mixed with $4.5 \mathrm{~mL}$ of brine solution and kept at $25^{\circ} \mathrm{C}$ for $24 \mathrm{~h}$ under the light and then dead nauplii were counted [14]. Experiments were held together with control and five different concentrations (10$1000 \mu \mathrm{g} / \mathrm{mL}$ ) of the extract in a set of three tubes per dose. Analysis of the data was carried out by EPA Probit Analysis Program to find the $\mathrm{LC}_{50}$ values.

\section{RESULTS}

Five methods, including $\beta$-carotene/linoleic acid bleaching method, phosphomolybdenum method, DPPH radical scavenging activity, ferric reducing power and metal chelating activity were used to measure antioxidant activity in this study. The results of the antioxidant activities of $A$. fulvescens var. fulvescens are summarized in Table 1. Total flavonoid and phenolic contents of the extract were also evaluated as quercetin and gallic acid equivalents, respectively (Table 2).

Free radical scavenging activity of methanolic extract of $A$. fulvescens var. fulvescens was measured using DPPH assay. $\mathrm{IC}_{50}$ value of extract was $0.123 \mathrm{mg} / \mathrm{mL}$. $\mathrm{IC}_{50}$ values of BHA and BHT were 0.030 and $0.045 \mathrm{mg} / \mathrm{mL}$, respectively (Table 1). $\mathrm{IC}_{50}$ value is inversely related to antioxidant ability of the extract. It seems that the scavenging ability of the extract was less effective than that of BHA and BHT. Reducing power activity was evaluated by using $\mathrm{EC}_{50}$. The $\mathrm{EC}_{50}$ value of extract was found to be $0.133 \mathrm{mg} / \mathrm{mL}$ (Table 1). Lower $\mathrm{EC}_{50}$ value indicates higher antioxidant properties. Metal ion chelating activity of extract toward ferrous ions was also investigated. The chelating activity of extract was evaluated using EDTA as a standard (Table 1). The extract showed good chelating activity with the value of $15.64 \mathrm{mgEDTAEs} / \mathrm{g}$. Total

Table 1

Antioxidant activities of methanolic extract from $A$. fulvescens var. fulvescens (mean $\pm \mathrm{SD}$ )

\begin{tabular}{|l|c|c|c|c|}
\hline \multicolumn{1}{|c|}{ Sample } & $\begin{array}{c}\beta \text {-Carotene-linoleic } \\
\text { acid assay (\%) }\end{array}$ & $\begin{array}{c}\mathrm{DPPH} \text { assay } \\
\left(\mathrm{IC}_{50} \mathrm{mg} / \mathrm{mL}\right)\end{array}$ & $\begin{array}{c}\text { Ferric reducing power } \\
\text { activity } \\
\left(\mathrm{EC}_{50} \mathrm{mg} / \mathrm{mL}\right)\end{array}$ & $\begin{array}{c}\text { Metal chelating } \\
\text { activity } \\
(\mathrm{mgEDTAEs} / \mathrm{g})^{\mathrm{a}}\end{array}$ \\
\hline A. fulvescens & $75.08 \pm 0.04^{\mathrm{b}}$ & $0.123 \pm 0.003$ & $0.133 \pm 0.002$ & $15.64 \pm 0.16$ \\
\hline BHA & $90.02 \pm 0.10$ & $0.030 \pm 0.007$ & $0.051 \pm 0.004$ & $\mathrm{nt}$ \\
\hline BHT & $91.05 \pm 0.33$ & $0.045 \pm 0.006$ & $0.052 \pm 0.002$ & $\mathrm{nt}$ \\
\hline
\end{tabular}

${ }^{a}$ EDTAEs - EDTA equivalents; $n t$ - no tested; ${ }^{b}$ Values expressed are means \pm S.D. 
Table 2

Total antioxidant capacity, total phenolic and flavonoid contents of methanolic extract from A. fulvescens var. fulvescens

\begin{tabular}{|c|c|c|c|}
\hline Sample & TPC $^{\mathrm{a}}$ & TFC $^{\mathrm{b}}$ & TAC $^{\mathrm{c}}$ \\
\hline A. fulvescens & $35.03 \pm 0.04^{\mathrm{d}}$ & $18.45 \pm 0.03$ & $68.21 \pm 0.07$ \\
\hline
\end{tabular}

aTotal phenolic content (TPC) expressed as gallic acid equivalents (mgGAEs $\mathrm{g}^{-1}$ ).

bTotal flavonoid content (TFC) expressed as quercetin equivalents (mgQEs $\mathrm{g}^{-1}$ ).

cTotal antioxidant capacity (TAC) expressed as ascorbic acid equivalents (mgAEs $\mathrm{g}^{-1}$ ).

dValues expressed are means \pm S.D.

antioxidant activity of extract was investigated by phosphomolybdenum assay. Phosphomolybdenum method is based on the reduction of Mo (IV) to Mo (V) by the antioxidants and the subsequent formation of green phosphate/Mo (V) compounds with a maximum absorption at $695 \mathrm{~nm}$. In this assay, total antioxidant activity of extract was determined as $68.21 \mathrm{mgAEs} / \mathrm{g}$ (Table 2). Inhibition capacity of oxidation of the linoleic acid of extract was found as $75.08 \%$ (Table 1). Antioxidant activities of BHA and BHT were investigated in this assay. Inhibition activities of the linoleic acid of BHA and BHT were detected as $90.02 \%$ and $91.05 \%$, respectively.

Total phenolic and flavonoid content were determined as $35.03 \mathrm{mgGAEs} / \mathrm{g}$ and $18.45 \mathrm{mgQEs} / \mathrm{g}$, respectively (Table 2). As a part of the study, a rapid high performance liquid chromatographic method using a reversed-phase column and a diode array detector method was established. Using HPLC analysis, the quantitative results of identified phenolic compounds of A. fulvescens var. fulvescens are listed in Table 3.

Table 3

Phenolic components in the methanolic extract from $A$. fulvescens var. fulvescens $(\mathrm{mg} / \mathrm{g}$ extract) $($ mean $\pm \mathrm{SD})$

\begin{tabular}{|c|l|c|}
\hline No & \multicolumn{1}{|c|}{ Phenolic components } & A. fulvescens \\
\hline 1 & Gallic acid & $0.09 \pm 0.02$ \\
\hline 2 & Protocatechuic acid & $0.04 \pm 0.03$ \\
\hline 3 & 4-Hydroxybenzoic acid & $0.15 \pm 0.04$ \\
\hline 4 & Chlorogenic acid & $0.84 \pm 0.03$ \\
\hline 5 & Vanillic acid & $0.27 \pm 0.01$ \\
\hline 6 & Caffeic acid & $0.52 \pm 0.02$ \\
\hline 7 & $p$-Coumaric acid & $0.02 \pm 0.01$ \\
\hline 8 & Ferulic acid & $0.13 \pm 0.02$ \\
\hline 9 & Cinnamic acid & $0.11 \pm 0.01$ \\
\hline
\end{tabular}




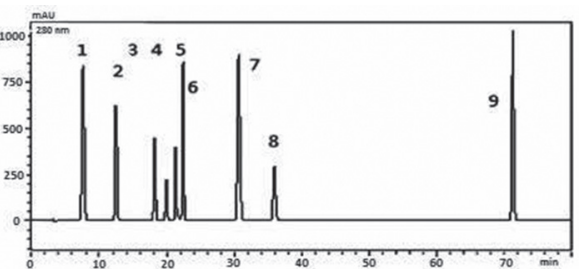

Fig. 1. HPLC chromatogram of standarts: 1. Gallic acid; 2. Protocatechuic acid; 3. 4-Hydroxybenzoic acid; 4. Chlorogenic acid; 5. Vanillic acid; 6. Caffeic acid; 7. $p$-Coumaric acid; 8. Ferulic acid; 9. Cinnamic acid

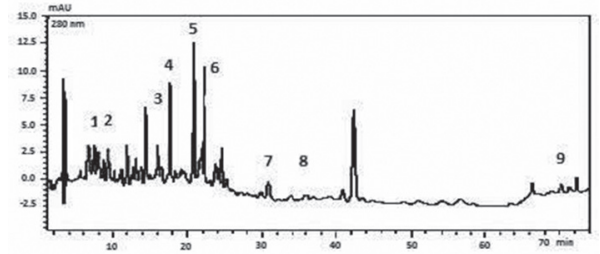

Fig. 2. HPLC chromatogram of phenolic components in the methanolic extract from A. fulvescens var. fulvescens, where: 1. Gallic acid; 2. Protocatechuic acid; 3. 4-Hydroxybenzoic acid; 4. Chlorogenic acid; 5. Vanillic acid; 6. Caffeic acid;

7. $p$-Coumaric acid; 8. Ferulic acid; 9. Cinnamic acid

Table 4

The LOD and LOQ values of phenolic components analyzed with HPLC

\begin{tabular}{|c|l|c|c|c|}
\hline No & \multicolumn{1}{|c|}{ Phenolic components } & $\begin{array}{c}\text { Retention time (RT), } \\
\text { min }\end{array}$ & LOD $(\mathrm{mg} / \mathrm{L})$ & LOQ $(\mathrm{mg} / \mathrm{L})$ \\
\hline 1 & Gallic acid & 7.8 & 0.014 & 0.083 \\
\hline 2 & Protocatechuic acid & 12.2 & 0.035 & 0.109 \\
\hline 3 & 4-Hydroxybenzoic acid & 18.1 & 0.018 & 0.072 \\
\hline 4 & Chlorogenic acid & 19.9 & 0.015 & 0.065 \\
\hline 5 & Vanillic acid & 22.1 & 0.112 & 0.164 \\
\hline 6 & Caffeic acid & 23.0 & 0.013 & 0.060 \\
\hline 7 & $p$-Coumaric acid & 30.3 & 0.010 & 0.055 \\
\hline 8 & Ferulic acid & 35.7 & 0.012 & 0.058 \\
\hline 9 & Cinnamic acid & 71.1 & 0.011 & 0.056 \\
\hline
\end{tabular}

Major phenolic compound was determined as chlorogenic acid ( $0.84 \mathrm{mg} / \mathrm{g}$ extract). HPLC chromatogram of phenolic standards and phenolic compounds in the extract were shown in Figures 1 and 2, respectively. Values for limit of detection (LOD) and limit of quantification (LOQ) were calculated for identification and quantification of phenolic compounds in the extract (Table 4).

The antibacterial activities of $A$. fulvescens var. fulvescens were evaluated by microdilution broth method. Increased concentrations of extracts caused decrease in survival of bacterial cells. The obtained results are shown in Table 5. Compared to Gram-negative bacteria tested, Gram-positive bacteria were less sensitive to the extract because the MIC values of the extract were observed as $95.4 \mathrm{mg} / \mathrm{mL}$ for B. subtilis and $83.2 \mathrm{mg} / \mathrm{mL}$ for $S$. aureus.

The BSLT was used for the preliminary screening for cytotoxicity of extract, as this assay has shown a good correlation with cytotoxicity assays with human cell lines and mouse bioassays [15]. The percentage of lethality was calculated from the 
Table 5

MIC values $(\mathrm{mg} / \mathrm{mL})$ of methanolic extract from $A$. fulvescens var. fulvescens against standard bacteria

\begin{tabular}{|l|c|c|c|}
\hline \multicolumn{1}{|c|}{ Microorganisms } & A. fulvescens & Gentamicin & Oxacillin \\
\hline Escherichia coli (ATCC 25922) & 25 & 3.12 & - \\
\hline Pseudomonas aeruginosa (ATCC 27853) & 3.12 & 6.25 & - \\
\hline Salmonella enteritidis (PT4) & - & 1.56 & - \\
\hline Staphylococcus aureus (ATCC 25923) & 83.2 & - & 6.25 \\
\hline Bacillus subtilis (NRRL B-209) & 95.4 & - & 3.12 \\
\hline Micrococcus luteus (NRRLB-1013) & 50 & - & 6.25 \\
\hline
\end{tabular}

mean death shrimp larvae of extracts treated tubes and control. The degree of lethality was found to be directly proportional to the concentration of the extract. The results of the BSLT are presented in Fig. 3. The extract of A. fulvescens var. fulvescens showed significant cytotoxicity with $\mathrm{LC}_{50}$ value of $37.71 \mu \mathrm{g} / \mathrm{mL}$ compared to Lepidium sativum $\mathrm{L}$., which is from the same family with $\mathrm{LC}_{50}$ value of $262.46 \mu \mathrm{g} /$ $\mathrm{mL}[32]$.

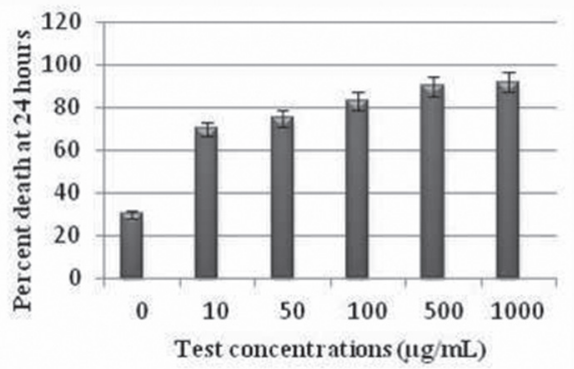

Fig. 3. The effects of methanolic extract from A. fulvescens var. fulvescens on the death percentage of brine shrimps

\section{DISCUSSION}

There are several ways to determine the antioxidant activities due to the complex nature of plant chemicals [7]. Measuring total phenolics and flavonoids is also important in association with their antioxidant activity, because phenolic compounds such as flavonoids and phenolic acids are known as powerful chain breaking antioxidants and may contribute directly to antioxidative activity [26]. $\mathrm{Fe}^{3+}$ reduction is often used to measure electron donation activity which is an important mechanism of antioxidants [6]. Therefore, in order to assess the electron-donating power of the extract, its ability to reduce $\mathrm{Fe}^{3+}$ was investigated. Ferrous ions are known as the most effective 
pro-oxidants in lipid peroxidation due to their high reactivity. In relation to this, the ability of substances or plant extracts to chelate iron can be important mechanism for antioxidant property [17].

The results of total phenolic and flavonoid content showed a similar tendency to the antioxidant abilities of the extract. In this context, the high content of total phenolics in the extract might be explain the strong antioxidant ability of A. fulvescens var. fulvescens. These results are in accordance with other reports in the literature, which showed strong relationship between antioxidant activities and total phenolic content $[9,24]$. Similar results were reported for some Alyssum species such as A. homolocarpum (F\&M.) Boiss by Souri et al. [30]. In a previous study, where 35 selected plants from Spain were compared in terms of their antioxidant activity, total phenolic content and skin care properties, A. serpyllifolium Desf. subsp. lusitanicum Dudley \& Silva leaf extract has exhibited high antioxidant activity and phenolic contents [19]. The highest phenolic compound found in in methanolic extract of $A$. fulvescens var. fulvescens was chlorogenic acid. Chlorogenic acid is well known as metal chelator and lipid peroxidation inhibitor in relation to its biological activities [21]. These data supported that the biological activities of A. fulvescens var. fulvescens could be attributed to its phenolics compounds. A previous study has revealed that $A$. maritimum (L.) Lam. leaf extracts act as a natural quorum sensing inhibitor with slight inhibition [13].

Brine shrimp lethality bioassay is a simple, high throughout cytotoxicity test of bioactive chemicals, toxins and herbal extracts. It is based on the killing ability of test compounds on a simple zoological organism-brine shrimp (A. salina L.) [12]. It is concluded that BSLT can be suggested as a valid method to evaluate the cytotoxic activity of plant extracts.

In conclusion, such detailed studies on phenolic composition and biological activities of methanolic extract from $A$. fulvescens var. fulvescens aerial parts has been conducted for the first time. Based on biological activity assays, antioxidant, antibacterial, and cytotoxic activity of the extract was revealed. The extract can be beneficial due to its biological activity, and further studies are needed to be performed to identify biologically active compounds such as glucosinolates as well as phenolic compounds.

\section{REFERENCES}

1. Aktumsek, A., Zengin, G., Guler, G. O., Cakmak, Y. S., Duran, A. (2013) Antioxidant potentials and anticholinesterase activities of methanolic and aqueous extracts of three endemic Centaurea L. species. Food Chem. Toxicol. 55, 290-296.

2. Arvouet-Grand, A., Vennat, B., Pourrat, A., Legret, P. (1994) Standardization of propolis extract and identification of principal constituents. J. Pharm. Belg. 49, 462-468.

3. Bednarek, P. (2012) Sulfur-containing secondary metabolites from Arabidopsis thaliana and other Brassicaceae with function in plant immunity. Chembiochem. 13, 1846-1859.

4. Caponio, F., Alloggio, V., Gomes, T. (1999) Phenolic compounds of virgin olive oil: influence of paste preperation techniques. Food Chem. 64, 203-209. 
5. Davis, P. H. (1965) Flora of Turkey and the East Aegean Islands. Vols 1-10, Edinburg Univ.

6. Dorman, H. J. D., Peltoketo, A., Hiltunen, R., Tikkanen, M. J. (2003) Characterization of the antioxidant properties of de-odourised aqueous extracts from selected Lamiaceae herbs. Food Chem. 83, $255-262$.

7. Du, G. R., Li, M. J., Ma, F. W., Liang, D. (2009) Antioxidant capacity and the relationship with polyphenol and vitamin C in Actinidia fruits. Food Chem. 113, 557-562.

8. Dudley, T. R. (1966) Ornamental madworts (Alyssum) and the correct name of the goldentuft Alyssum. Arnoldia 26, 33-45.

9. Ertaş, A., Gören, A. C., Haşimi, N., Tolan, V., Kolak, U. (2015) Evaluation of antioxidant, cholinesterase inhibitory and antimicrobial properties of Mentha longifolia subsp. noeana and its secondary metabolites. Rec. Nat Prod. 9, 105-115.

10. Fahey, J. W., Zalcmann, A. T., Talalay, P. (2001) The chemical diversity and distribution of glucosinolates and isothiocyanates among plants. Phytochemistry 56, 5-51.

11. Hall, J. C., Sytsma, K. J., Iltis, H. H. (2002) Phylogeny of Capparaceae and Brassicaceae based on chloroplast sequence data. Am. J. Bot. 89, 1826-1842.

12. Harwig, J., Scott, P. M. (1971) Brine shrimp (Artemia salina L.) larvae as a screening system for fungal toxins. Appl. Microbiol. 2, 1011-1016.

13. Kalia, V. C. (2013) Quorum sensing inhibitors: An overview. Biotechnol. Adv. 31, 224-245.

14. Krishnaraju, A. V., Rao, T. V. N., Sundararaju, D., Vanisreeb, M., Tsayb, H. S., Subbaraju, G. V. (2005) Assessment of bioactivity of Indian medicinal plants using brine shrimp (Artemia salina) lethality assay. Int. J. Appl. Sci. Eng. 3, 125-134.

15. Lee, T. H., Chen, Y. M., Chou, H. N. (1999) Toxicity of cyanobacterial strains using Artemia salina in comparison with the mouse bioassay. Acta Zoologica Taiwanica 10, 1-8.

16. Mammadov, R. (2014) Secondary Metabolites in Spermatophyta. Nobel Press, Ankara, Turkey.

17. Manian, R., Anusuya, N., Siddhuraju, P., Manian, S. (2008) The antioxidant activity and free radical scavenging potential of two different solvent extracts of Camelia sinensis (L.) O. Kuntz, Ficus bengalensis L. and Ficus racemosa L. Food Chem. 107, 1000-1007.

18. Mart, S. (2006) An Ethanobotanical Investigation of the Natural Plants Using by Inhabitants in Bahce and Hasanbeyli Districts of Osmaniye Province. MSc Thesis. Univ. Inst. Nat. and Appl. Sci., Dept. of Biol., Cukurova, Turkey.

19. Martínez, A., Estévez, J. C., Silva-Pando, F. J. (2012) Antioxidant activity, total phenolic content and skin care properties of 35 selected plants from Galicia (NW Spain). Front Life Sci. 6, 77-86.

20. NCCLS (National Committee for Clinical Laboratory Standards). (1999) Performance standards for antimicrobial susceptibility testing. 9th International Supplement. M100-S9, Wayne Pa.

21. Oksana, S., Marian, B., Mahendra, R., Bo, S. H. (2012) Plant phenolic compounds for food, pharmaceutical and cosmetics production. J. Med. Plants Res. 6, 2526-2539.

22. Oyaizu, M. (1986) Studies on products of browning reactions: Antioxidative activities of browning reaction prepared from glucosamine. Jpn J. Nutr. 44, 307-315.

23. Ozay, C., Mammadov, R. (2016) Assessment of some biological activities of Alyssum L. known as madwort. Acta Pol. Pharm. Drug Res. 73, 1213-1220.

24. Ozay, C., Mammadov, R., Tasdelen, G., Karagur, E. R., Akca, H. (2015) Potential antioxidant, antiproliferative and hepatoprotective effects of Crataegus meyeri. J. Food Biochem. 39, 548-553.

25. Prieto, P., Pineda, M., Aguilar, M. (1999) Spectrophotometric quantitation of antioxidant capacity through the formation of a phosphormolybdenum complex: specific application to the determination of vitamin E. Anal Biochem. 269, 337-341.

26. Shahidi, F., Wanasundara, P. K. J. P. D. (1992) Phenolic antioxidants. Crit. Rev. Food Sci. Nutr. 32, 67-103.

27. Shimer, H. W. (1943) Origin and Significance of Plant Names. South Shore Nature Club, Hingham/ Massachusetts.

28. Slinkard, K., Singleton, V. L. (1977) Total phenol analyses: automation and comparison with manual methods. Am. J. Enol. Vitic. 28, 49-55. 
29. Sokmen, A., Gulluce, M., Akpulat, H. A., Daferera, D., Tepe, B., Polissiou, M., Sokmen, M., Sahin, F. (2004) The in vitro antimicrobial and antioxidant activities of the essential oils and methanol extracts of endemic Thymus spathulifolius. Food Control 15, 627-664.

30. Souri, E., Amin, G., Farsam, H., Barazandeh Tehrani, M. (2008) Screening of antioxidant activity and phenolic content of 24 medicinal plant extracts. DARU J. Pharm. Sci. 16, 83-87.

31. Wu, C., Chen, F., Wang, X., Kim, H. J., He, G., Haley-Zitlin, V., Huang, G. (2006) Antioxidant constituents in fever few (Tanacetum parthenium) extract and their chromatographic quantification. Food Chem. 96, 220-227.

32. Zia-Ul-Haq, M., Shah, M. R., Qayum, M., Ercisli, S. (2012) Biological screening of selected flora of Pakistan. Bio Res. 45, 375-379. 